\title{
THE IMPACT OF THE MANAGER'S PERSONAL DEVELOPMENT ON MANAGERIAL PRACTICES: METHODOLOGICAL APPROACHES AND CASE STUDY
}

\author{
Florentina IONESCU (CIULEI) ${ }^{a *}$, Angela MORLOVEA ${ }^{b}$, Diana Nicoleta GEORGESCU \\ Delia Mioara POPESCU ${ }^{d}$, Constanța POPESCU ${ }^{e}$, \\ Elena ANGHEL \\ a,b,c,d,e,f Valahia University of Targoviste, Romania
}

DOI: $10.24818 / \mathrm{IMC} / 2020 / 02.06$

\begin{abstract}
Contemporary society, in continuous transformation, requires school organizations to reconfigure the role and status of the school manager. Today, the manager must no longer be the one who holds the information, but on the contrary, he must open up, share the space for decisions, empower, inspire confidence and be able to increase the involvement of his employees in order to achieve performance. To do this, he must acquire new competences in the personal sphere. The manager who is involved in a process of personal development, researches himself the means to acquire a better self-awareness, makes an in-depth reflection on himself, his values, his personal goals, his relationships with other members of the organization, harmonizes them with those of employees and of the organization. For the manager, self-awareness is the fundamental factor of his future performance and that of the organization. He must be able to take a realistic and critical view of his own dispositions, resources, motivations and beliefs. This deep knowledge of himself will allow him to increase his positive influence on his teams and his environment, to manage change and resistance to change. The methodology of the present study consisted of rigorous analysis of the literature and empirical research based on questionnaire survey. The main conclusions of the study refer to the degree of involvement in the personal development process of the manager which is reflected on their managerial practices.
\end{abstract}

KEYWORDS: self-awareness, personal development, leadership, school organization, organizational change.

\section{INTRODUCTION}

The changes imposed by the educational reforms can determine the school manager to question his managerial practices and his competences. This questionnaire leads him to a process of reflection on himself and his relationships with others in the organization. He faces new situations in his organization, which he does not feel ready to manage, noticing a gap between his current competences and those required by the roles imposed by the new educational contexts. Moreover, he will not be able to respond to these new situations, relying only on his professional competences, as a result, the manager should train the necessary competences by getting involved in a development process.

Conviced that the managerial practices are influenced by personal development, by the involvement of the manager in the processes of (self) reflection, on both himself and his employees, we propose to identify those personal and leadership qualities that can be the premises of effective managerial practices. These practices can be taken over by practitioners in the field of school management and introduced into current practice, thus reaching their generalization.

\footnotetext{
${ }^{*}$ Corresponding author. E-mail address: ciuleiflorentina@gmail.com
} 
In the present study we want to highlight the impact, but also the importance of the personal development process, in which the manager is deliberately involved, on his managerial practices, on the relations with the employees and, consequently, on the school organization.

Reviewing and improving these generalized managerial practices, by going through the process of personal development, lead to increasing the quality of educational services provided by the organization: by stimulating the innovative and creative potential of employees, by acquiring new personal competences, by increasing adaptability to change, by creating a favorable psychological work climate based on self and mutual confidence.

There are three challenges: managing the goal, managing the interactions and managing the organization. The manager should be a compass more than a clock, to inspire, to stimulate, to empower, and his vision must evolve towards a management based on confidence: in himself, in the other and in the future (Bratchenko, 1997), facilitating change and promoting the evolution of the organization and its performance.

In the last two decades, in the private business environment there has been a growing concern for the personal development of both managers and employees of companies by introducing in the initial and continuing training of managers, practices for developing management, leadership and coaching competences (Whetten, 2011). The novelty of the present study is the analysis of the personal development phenomenon of managers from educational system and the impact of their reflective managerial practices at the level of the school organization.

\section{MANAGER'S PERSONAL DEVELOPMENT - METHODOLOGICAL APPROACHES}

Personal development can be defined as an action of human resources management, which aims to increase the competences of employees, but also to improve the quality of life and the relational climate at work. Beyond the methods, objective techniques and tools used by the manager, various personal development practices have emerged, which is a more humane approach of the organization, being a first step in its development, because performance is measured by the competences of its employees. In the context of defining personal development from an organizational perspective, Armstrong stated that "a key element of human resource development is personal development which represents the increase of an individual's ability and the cultivation of his potential by going through learning and education experiences" (Armstrong, 2005), and from the perspectives of management sciences is "the ability of a man to invite the others to progress with him towards a vision" in the case of any organization, in the person of manager.

The process of personal development can have two dimensions: the one imposed by the organization or system and the deliberate one (Marin, 2002).

a) In the case of the imposed process, the effects on the performance of the manager's role will not always satisfy the expectations of the school organization. The explanation could be this: in response to an imposed development, the manager in a professional situation could resist to the change he has to face, he could be determined to retire, to react in order to comply with the rule.

b) On the other hand, when this development is freely chosen, manager align his personal goals with those of the school, and this is due to the fact that he may develop the potential and can gain confidence and fulfillment of his role.

In other words, the manager perceives development approaches as an opportunity to benefit from it in fulfilling his role. The manager who takes a personal development process seeks out only the means to gain a better understanding of himselve, makes an in-depth reflection on himself, on his values, on his personal goals, on his relationships with other members of the organization.This could lead him to change his attitudes and behaviors, to better understanding his own functioning, because they are based on his values and are in the service of his personal goals, it would allow him to gain consistency with himself. Aware of his own functioning, he would constantly seek an adequacy between his attitudes, behaviors, values and goals. If the manager is able to understand well his functioning through self-awareness, he understands better the functioning of others (Sosik, 
2001). Understanding that his attitudes and behaviors are determined, among other things, by his personal values and goals, the manager would perceive and accept in his colleagues the same determinants, as a result, could predict the attitudes and behaviors they are likely to adopt depending on situation. Self-awareness, self-reflection and acceptance can help the managers understand better the expectations and needs of their employees, to listen empathetically without issuing an objective assessment or judgment on them.

\subsection{Self-awareness - the path of personal development of the manager}

Relating to the managerial perspective, before leading other people, it is essential that the manager knows himself well. In Bourner's view, a dimension of personal development through selfawareness refers to a person's determination to be aware of the drivers who control their behaviors (Bourner, 1996). Self-awareness through introspection passes through the filter of one's own opinion about oneself, with the temptation to exaggerate, to minimize some of one's mistakes. Therefore, it is essential for the manager to consider the reactions of his employees, colleagues and superiors to the manifestations in the outside world of his thinking, his feelings, attitudes and behaviors. These reactions, even if they cannot be completely objective, will lead to a better knowledge of the manager's self through the effect called "mirror" that will allow the manager to change his attitudes and behaviors. Continuing this direction, Sosik defines the manager's selfawareness as an agreement between the manager's self-evaluation, his leadership and the evaluation made by his employees (Sosik, 2001). For the present investigative approach, the manager's selfawareness presume a good knowledge and self-understanding related to his attitudes, behaviors, strengths and weaknesses.

Self- awareness as a result of personal development allows school managers to change their attitudes and behaviors, because it makes aware of them, as well as their impact on other actors in the school organization. Self-awareness builds the manager's self-confidence, which influences his managerial competences. Self-confidence, essential in the managerial act, derives from selfawareness, from the knowledge of competences, shortcomings, talents and weaknesses, it gradually develops by exploiting the strengths and remedying the weak ones. The art of leadership is primarily a search for self, with self-awareness comes the confidence necessary for the act of leadership (Kouzes, 1991).

Self- awareness allows managers to get to know their employees better, to plan more realistic expectations of them, and also allows them to listen empathetically. Goleman also pointed out that understanding other people's emotional field requires a great deal of familiarity with one's own (Goleman, 1999), and Rogers notes that trust in another person's competence, judgment, solidarity, or sensitivity leads to a greater openness to it. The feeling of trust also urges you to be more receptive (Rogers, 1998).

The manager's coherence with himself, which he could acquire as a result of a personal development process, would strengthen his credibility with his employees, as well as his selfconfidence. This could be explained by the fact that the manager would easily succeed to consolidate his actions and speeches. Employees would perceive him and see him as a role model, as someone who is able to "say what he will do, do what he said and say he did." This perception comes from the certainty regarding the attitudes and behaviors of the manager who acts in accordance with the image he offers. Employees would perceive a reduction in the risk of trust in the manager. As a result, the manager would be credible in the eyes of his employees and would be "trustworthy".

In addition, a better understanding and acceptance of the expectations and needs of his employees, would allow the manager to create a relationship of mutual confidence. For a better understanding of the employees, the manager could identify, relevance, needs, expectations and their personal objectives. By knowing and understanding his employees, the manager would also be determined to trust their competences. 


\subsection{Confidence in the manager - predictor of the involvement of employees from school organization}

Confidence is mandatory for optimizing a system and involved in the education system. Lack of confidence causes each component to pursue its own immediate interests to the detriment of the long-term ones and to the detriment of the entire system (Deming, 1994). In the opinion of Kouzes and Pozner, confidence is the cornerstone of human relations, inside and outside the organization (Kouzes, 1991). Confidence is also a key element for organizational effectiveness.

In our investigative approach we will choose two guidelines for this concept. The first orientation is the manager's self-confidence, on the one hand, because it comes from self- awareness and, on the other hand, because it is an essential condition of his leadership. This idea is supported by Kouzes and Pozner (1991) who state that self-confidence, essential for leadership, comes from selfawareness, knowledge of competences, deficiencies, talents and weaknesses. Mutual confidence between the manager and his employees is the second orientation we have given to the concept. We considered that the reciprocity of this relationship is essential to obtain the necessary conditions for employee involvement. Similarly, for Coriat and Guennif, the relationship of confidence results from a process, it was built step by step (Coriat, 2000). However, the relationship of confidence between two agents can only be developed on the basis of reciprocity.

Through their position, school managers are directly responsible for building a relationship of confidence by creating a favorable psychological climate within the school organization. Blau defines confidence as the belief that a person's own commitment and word is safe and will be honored in an exchange relationship (Blau, 1993). Moreover, Pruit states that the confidence is a critical element in the exchange relationship, because it conditions the existence of a constructive dialogue and cooperation in problems solving (Pruit, 1981).

In a school organization, the ability of management to develop and maintain a long-term relationships of mutual confidence with their employees is an essential condition for the success of the organization. Although confidence is not the only factor that influences the relationship between the manager and his employees, those who confidence their manager show greater satisfaction in their work, experience fewer role conflicts and express more favorable opinions to their manager.

By virtue of its position, between management and employees, the school manager has the mission to establish the conditions for employee involvement and thereby achieve greater performance in the organization, in relation to its fundamental mission to provide quality educational services, the whole school community. Involvement depends on employees' perceptions of the psychological climate of work, which, in turn, is influenced by the confidence they have in their manager (Lagace, 1991).

\section{PERSONAL DEVELOPMENT OF MANAGER - KEY ELEMENT IN ORGANISATIONAL CHANGE}

Looking carefully around us, we notice that everything is changing. Change takes place at different levels. The events that occur in a person's life are multiple and they determine the need for continuous adaptation to change. Change does not only take place at the level of individuals, it can also take place at the level of a group of people, at the level of a department within an organization, but the engine of triggering the process of change is the individual. According to the principle of the insufficient mandate of Professor Reginald Revans, those who are not able to change cannot change what is around them. Complementing Professor Revans' principle with that of insufficient selfawareness, those who do not know each other are unable to change themselves (Revans, 1971). In order to facilitate changes in the content, direction and dynamics of the manager's personal development process, it is necessary to meet certain rules set out as general criteria. 
Table 1. General criteria of personal development

\begin{tabular}{|l|l|}
\hline $\begin{array}{c}\text { Intrapersonal (changes that take place in the } \\
\text { inner world of the person in relation to himself) }\end{array}$ & $\begin{array}{l}\text { Interpersonal (changes that take place in the } \\
\text { external world - in relation to others) }\end{array}$ \\
\hline $\begin{array}{l}\text { Self-acceptance: appreciation, self-love and the } \\
\text { ability to respect yourself for your decisions. }\end{array}$ & $\begin{array}{l}\text { Acceptance of others, respect for people, } \\
\text { fairness. }\end{array}$ \\
\hline $\begin{array}{l}\text { Opening personal experience and emotional } \\
\text { experiences to accumulate new experiences. }\end{array}$ & $\begin{array}{l}\text { Understanding others. A mature person will } \\
\text { personally appreciate the situations and will } \\
\text { have a differentiated vision of the } \\
\text { consequences, minimizing stereotypical } \\
\text { thoughts. Ability to initiate interpersonal } \\
\text { communication based on understanding, } \\
\text { awareness, empathy. }\end{array}$ \\
\hline $\begin{array}{l}\text { Self-understanding, the ability to hear yourself, to see } \\
\text { yourself authentically. Now that the masks and } \\
\text { defense mechanisms are minimized, the sensitive } \\
\text { changes of the person, the flexibility and the vision } \\
\text { appropriate to the changes in life, the accumulation } \\
\text { of experience that approaches the ideal correlation: } \\
\text { the real ego from the ideal ego. }\end{array}$ & $\begin{array}{l}\text { Socialization, the ability to be constructive in } \\
\text { social relationships with others, to live with } \\
\text { others in the best possible harmony. }\end{array}$ \\
\hline $\begin{array}{l}\text { Responsibility for personal updating, openness, } \\
\text { freedom. }\end{array}$ & $\begin{array}{l}\text { firm position, to be open to meet problems, } \\
\text { adapting a personal creativity in solving them; } \\
\text { creative adoption of new, concrete situations } \\
\text { and the ability to use internal potentials to the } \\
\text { fullest. }\end{array}$ \\
\hline change while maintaining its identity & \begin{tabular}{l} 
Creative adaptation - is a profound quality of a \\
\hline mature person, through the attitude of taking a
\end{tabular} \\
\hline
\end{tabular}

Source:adapted from Bratchenko and Mironova (1997)

As detailed in the graphic organizer above, all the changes presented are made by specific personal laws, and the transformations that have occurred at the level of one dimension will be reflected on the others.

In Handbook of Management Consultants (1992), Professor Kubr defines levels of change in our investigative approach we focus on individual change in relation to changing the culture of the organization to which they belong, and their resistance to change.

In any case regardless of the intensity of change, the school manager will face resistance to change during the managerial activity, especially of employees, who when they are not motivated and do not impose a firm decision, will become vulnerable and reluctant to change. This individual resistance to change goes through three levels (Maurer, 2009):

a) Level I of resistance or rational level, is generated by the insufficiency of the data related to the proposed change, by a poor communication, by the disagreement with the change and by the ambiguity regarding the significance of the change.

b) Level II of resistance or emotional level is installed when the reaction is an emotional response to change, rooted in fear, and fear is generated by the desire to survive, communication being difficult. 
c) Level III of resistance or relational level aims to trigger resistance towards the person who imposes change out of a lack of trust.

As the negative reaction in any process of organizational change comes from employees and the organizational hierarchy becomes more difficult to achieve this. For any member of the organization, and especially for its manager, self-development is very important, especially if the latter aims to be followed by the others.

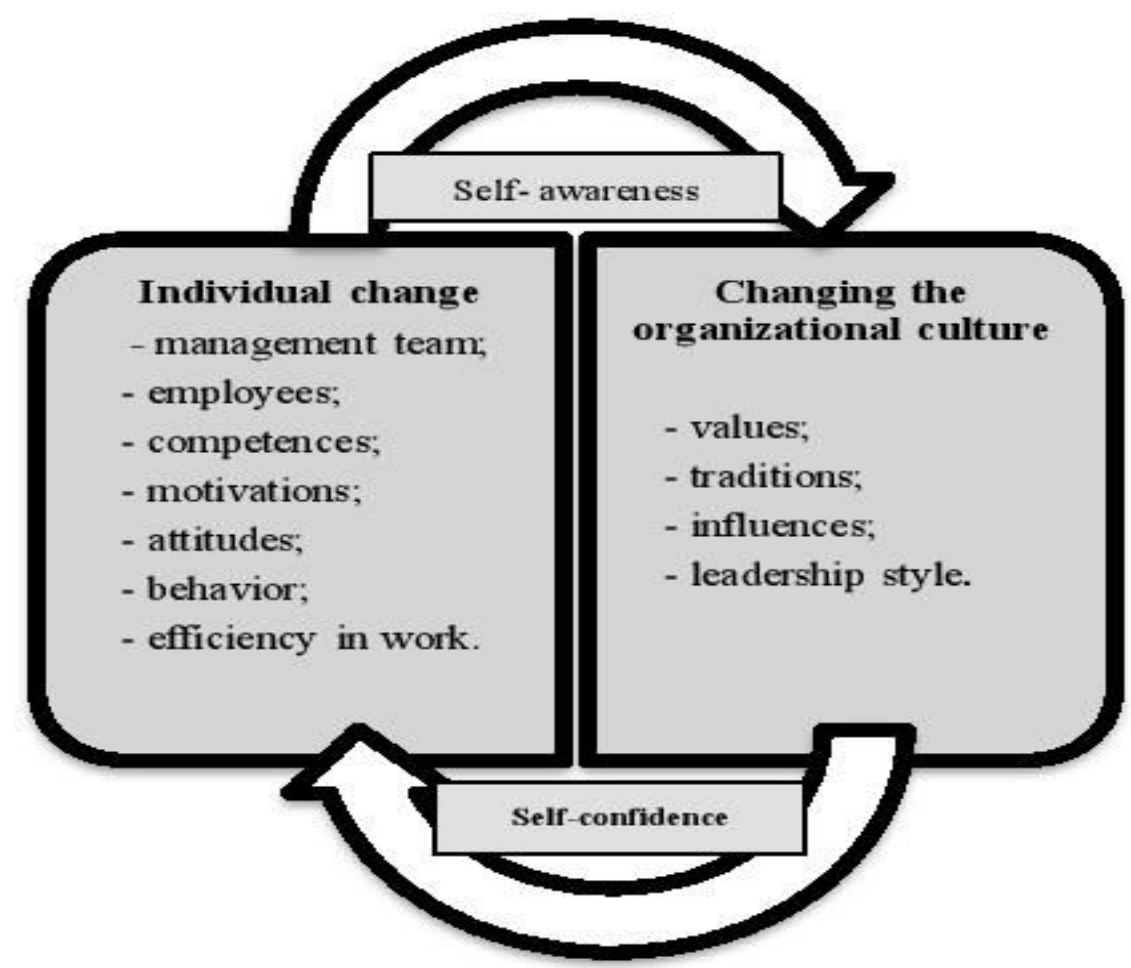

Figure 1. Implications of change

Source:adapted from Kubr (1992).

\subsection{Leadership - a practice of personal development}

Personal development is a component of leadership development because it refers to a continuous improvement of the manager's personal qualities and implicitly to his reflective managerial practices with an impact on organizational performance.

For the manager to develop personally and professionally, it is necessary to have perseverance, to be determined, cooperative and to have a strategy to build, over time, a leading personality. To be truly a good leader he needs a multitude of qualities such as: social qualities, an self-awareness through which to succeed in understanding human nature, but very important and absolutely indispensable is confidence.

In addition to all these qualities, many others are added that can be born or acquired later and then developed. In a general sense, leadership consists of 19 qualities: decision-making ability, energy, humor, sense of justice, determination, ambition, personal example, self-control, loyalty, sense of duty, calm, self-confidence, responsibility, empathy, initiative, courage, firmness and enthusiasm (Adair, 2014).

In our investigative approach we will focus on those qualities that are integrated into the reflective dimension of the manager, as a result of involvement in a process of personal development, as shown in the graphic organizer below (Figure 2).

Therefore, the reflective dimension of the manager has a significant impact on the entire school organization, as it can contribute to its permanent adaptation to social dynamics, increasing the quality of educational services it provides and, implicitly, achieving performance. 


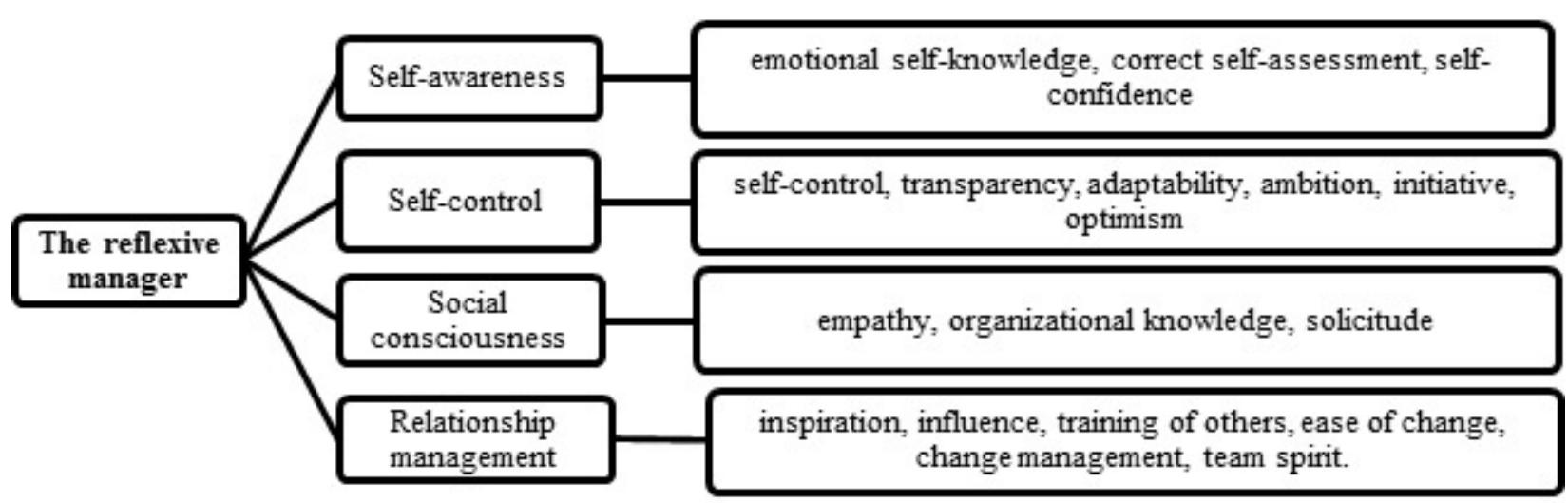

Figure 2. The reflexive manager

Source: adapted from Goleman et al. (2002)

\section{RESEARCH ON MANAGERS' PERCEPTION OF THE IMPACT OF PERSONAL DEVELOPMENT ON MANAGERIAL PRACTICES}

In order to carry out the research, the analysis of the specialized literature, of the legislative documents from the international and national space was used, the quantitative method was applied - the survey based on a questionnaire, which represents an efficient way of collecting the primary data (Dinu et al., 2017).

The purpose of this research is to conduct an analysis of managers' perceptions of the impact of personal development on managerial practices.

The general objective of the research aims to assess the degree of interest of school managers in Dâmbovitg, regarding personal development as a process of change and is detailed below according to the 3 specific objectives, from which derive 5 hypotheses of this research, highlighted in Table 2.

Table 2. Specific objectives and research hypotheses

\begin{tabular}{|l|l|}
\hline \multicolumn{1}{|c|}{ Specific objectives } & \multicolumn{1}{|c|}{ Research hypotheses } \\
\hline $\begin{array}{l}\text { O1:Reflective management } \\
\text { practices are influenced by personal } \\
\text { development. }\end{array}$ & $\begin{array}{l}\text { Hypothesis 1.1. Over 50\% of managers reflect on } \\
\text { attitudes, behaviors, values and and personal goals. } \\
\text { Hypothesis 1.2. Over 50\% of managers adopt } \\
\text { participatory practices in the relationship with } \\
\text { employees. }\end{array}$ \\
\hline $\begin{array}{l}\text { O2: The challenges posed by the } \\
\text { change process can be overcome } \\
\text { through personal development } \\
\text { practices. }\end{array}$ & $\begin{array}{l}\text { Hypothesis 2.1. Over 50\% of managers take into } \\
\text { account the opinions of employees regarding the } \\
\text { process of organizational change. } \\
\text { Hypothesis 2.2. Does the manager's self-awareness } \\
\text { influence self-confidence and increase his credibility } \\
\text { with employees? }\end{array}$ \\
\hline $\begin{array}{l}\text { O3: Leadership and personal } \\
\text { qualities of school managers } \\
\text { contribute to the efficiency of } \\
\text { reflective managerial practices. }\end{array}$ & $\begin{array}{l}\text { Hypothesis 3.1. Over 5\% of the surveyed managers } \\
\text { focus on qualities such as: team spirit and } \\
\text { collaboration, visionary thinking, self-assessment, self- } \\
\text { improvement, self-confidence and self - control. }\end{array}$ \\
\hline
\end{tabular}

Source: authors 
In order to carry out this research, the questionnaire was applied for a number of 51 school and preuniversity education managers from Dâmbovița. In the context of the epidemiological situation caused by the spread of SARS-CoV-2, the questionnaire was submitted online, via Google Forms, between 1 and 10 September 2020. This type of online survey based on a questionnaire has advantages, such as: selecting the most appropriate online distribution channels, lack of costs, enough time to think about the formulation of answers by respondents, lack of stress in formulating them.

\subsection{Results and discussions}

The questionnaire was distributed to 51 school managers from Dâmbovița pre-university education, of which $58.82 \%$ women and $41.18 \%$ mens, that it is their age range $30-40$ years, 10 respondents (19.6\%) between 41-50 years old there are 11 respondents $(21.6 \%)$, between 51-60 years old there are 22 respondents $(43.1 \%)$, over 60 years old there are 8 respondents $(15.7 \%)$ and they work at preschool level (15 managers- 29.4\%), at primary level (6 managers - 11.8\%) and at gymnasium level (30 managers - 58.8\%). With reference to the school organization, 25 managers are from urban areas (49\%) and 26 managers from rural areas (51\%), and 3 managers $(5.9 \%)$ have less than 20 employees, 22 managers $(43,1 \%)$ have between 21 and 50 employees, 20 managers $(39.2 \%)$ have between 51 and 100 employees and 6 managers (11.8\%) have over 100 employees.

The information gathered with the help of the questionnaire was processed in the SPSS computer system. The results of the processing were analyzed, interpreted, and the hypotheses were verified (Ristea et al., 2020).

With reference to the first section of the questionnaire - the degree of appreciation of school managers on reflective management practices, respondents were asked to assess the frequency with which different situations occur in their managerial practice, recording the following:

a) managers reflect on attitudes, behaviors, values and personal goals: $68.6 \%$ very often, $25.5 \%$ frequently, $2 \%$ rarely, and $3.9 \%$ never;

b) managers reflect on the attitudes, behaviors, values and objectives of employees in the organization: $62.7 \%$ very often, $33.3 \%$ frequently, $2 \%$ rarely, and $2 \%$ never;

c) managers encourage employees to participate in important decisions: $62.7 \%$ very often, $31.4 \%$ frequently, $3.9 \%$ rarely, and $2 \%$ never;

d)managers are looking for ways to improve the organization's performance: $64.7 \%$ very often, $31.4 \%$ frequently, $2 \%$ rarely, and $2 \%$ never;

e) managers take into account the opinions of employees regarding a change: $54.9 \%$ very frequently, $29.4 \%$ frequently, $13.7 \%$ rarely, and $2 \%$ never;

f) managers state that employees can request their help for any confusion related to the change: $68.6 \%$ very frequently, $19.6 \%$ frequently, $9.8 \%$ rarely, and $2 \%$ never;

g) managers appreciate employees who successfully and timely meet their objectives: $66.7 \%$ very frequently, $25.5 \%$ frequently, $5.9 \%$ rarely, and $2 \%$ never;

From the below-presented results (graph 1-4) it can be seen that in their practice more than $50 \%$ of managers are involved in a process of reflection on their attitudes, behaviors, values and personal goals, but also on those of their employees and that encourages them to participate in important decision-making, supports employees and takes their views into account in the change process, validating hypothesis 1.1. and 1.2. 
Graph 1. Managers' reflection on personal attitudes, behaviors, values and objectives.

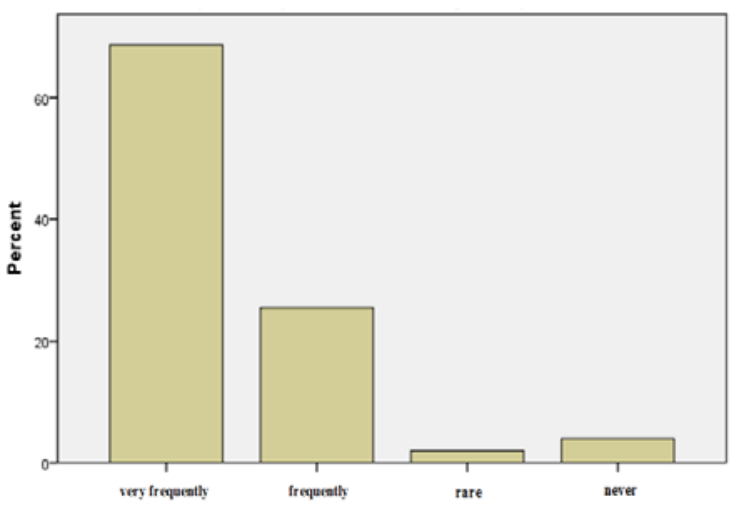

Graph 3. The manager takes into account the employees' opinions regarding the change

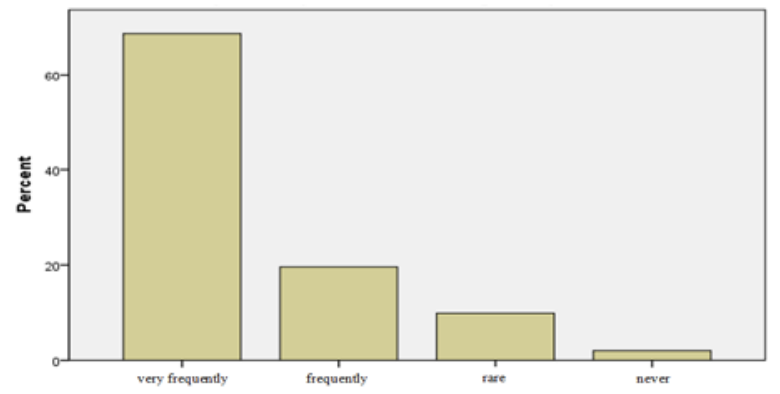

Graph 2. The manager encourages employees to participate in making important decisions

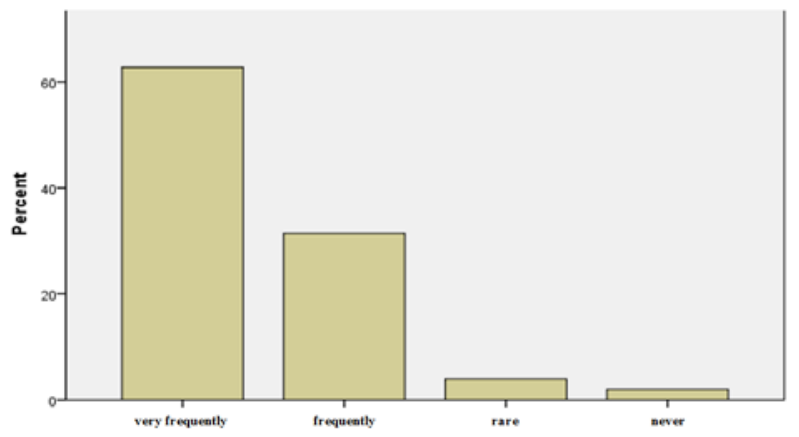

Graph 4. The manager appreciates employees who perform their tasks successfully

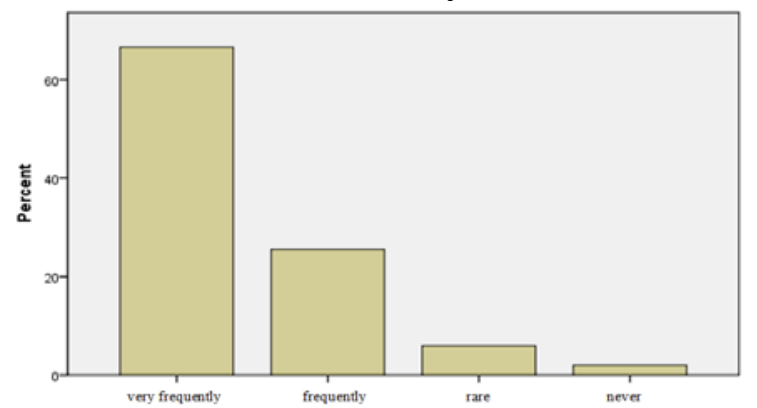

In the second section of the questionnaire - the perception of managers on their own school organizations, the respondents expressed their agreement or disagreement with certain statements, recording the following:

a) For the statement Self- awareness as a result of personal development allows school managers to change their attitudes and behaviors $72.5 \%$ of managers are in total agreement, $19.6 \%$ partially agree, $2 \%$ neutral, $2 \%$ partially disagree, $3.9 \%$ total disagreement;

b) For the statement My values coincide with the values of the organization $58.8 \%$ of the managers are in total agreement, $33.3 \%$ partially agree, $3.9 \%$ neutral, $2 \%$ partially disagree, $2 \%$ totally disagree;

c) For the statement Through a better understanding of the employees, they can identify their needs, expectations and personal objectives $60.8 \%$ of the managers are in total agreement, $29.4 \%$ partially agree, $5.9 \%$ neutral, $3.9 \%$ totally disagree;

d) For the statement, the Organization has qualified and valuable employees, $51 \%$ of the managers are in total agreement, $41.2 \%$ partially agree, $5.9 \%$ neutral, $2 \%$ totally disagree;

e) For the statement From self- awareness derives the confidence wich is necessary for the act of management $62.7 \%$ of managers are in total agreement, $25.5 \%$ partially agree, $5.9 \%$ neutral, $2 \%$ partially disagree, $3.9 \%$ totally disagree;

f) For the statement The coherence of the manager with himself strengthens his self-confidence $70.6 \%$ of the managers are in total agreement, $19.9 \%$ partially agree, $5.9 \%$ neutral, $2 \%$ partially disagree, $2 \%$ totally disagree; 
g) For the statement The coherence of the manager with himself consolidates his credibility towards his employees $68.6 \%$ of the managers are in total agreement, $25.5 \%$ partially agree, $2 \%$ neutral, $3.9 \%$ partially disagree;

h) For the statement, the Manager is responsible for building a relationship of mutual confidence with its employees $58.8 \%$ of managers are in total agreement, $31.4 \%$ partially agree, $7.8 \%$ neutral, $2 \%$ partially disagree;

i) For the statement Empathic communication with subordinate employees takes place constantly $64.7 \%$ of managers are in total agreement, $23.5 \%$ partially agree, $7.8 \%$ neutral, $3.9 \%$ partially disagree;

j) For the statement Change is a positive thing 51\% of managers are in total agreement, 35.3\% partially agree, $9.8 \%$ neutral, $2 \%$ partially disagree, $2 \%$ totally disagree;

k) For the statement Change is a necessity for the organization $51 \%$ of managers are in total agreement, $37.3 \%$ partially agree, $5.9 \%$ neutral, $3.9 \%$ partially disagree, $2 \%$ totally disagree;

1) For the statement $I$ am satisfied with my managerial practices $52.9 \%$ of managers are in total agreement, $37.3 \%$ partially agree, $5.9 \%$ neutral, $2 \%$ partially disagree, $2 \%$ totally disagree;

$\mathrm{m})$ For the statement I am satisfied with the current situation of the organization $52.9 \%$ of managers are in total agreement, $35.3 \%$ partially agree, $3.9 \%$ neutral, $5.9 \%$ partially disagree, $2 \%$ totally disagree.

Graph 5. The values of the manager coincide with the values of the organization

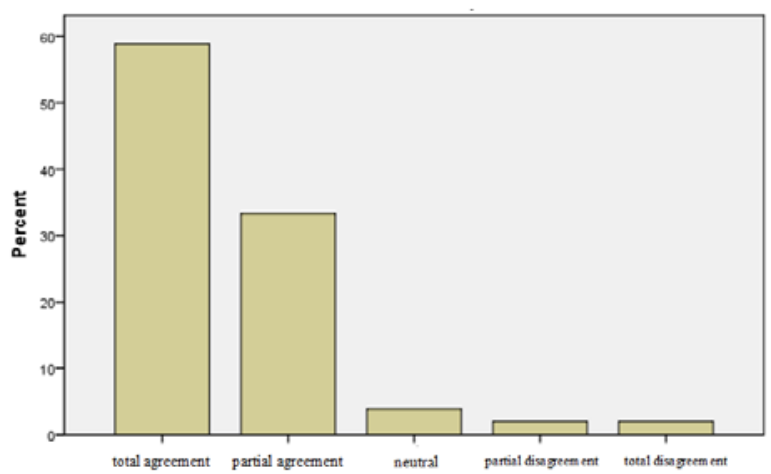

Graph 7. Self- awareness as a result of personal development allows school managers to change their attitudes and behaviors

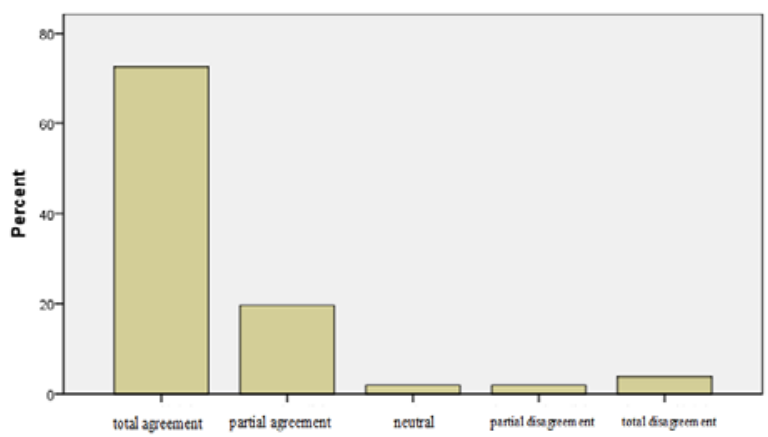

Graph 6. The organization has qualified and valuable employee

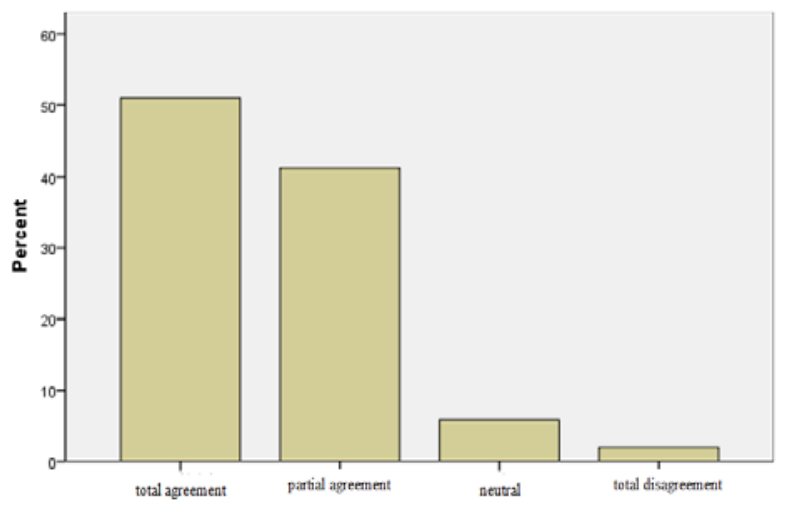

Graph 8. By knowing and understanding employees, the manager is determined to have confidence in their competences

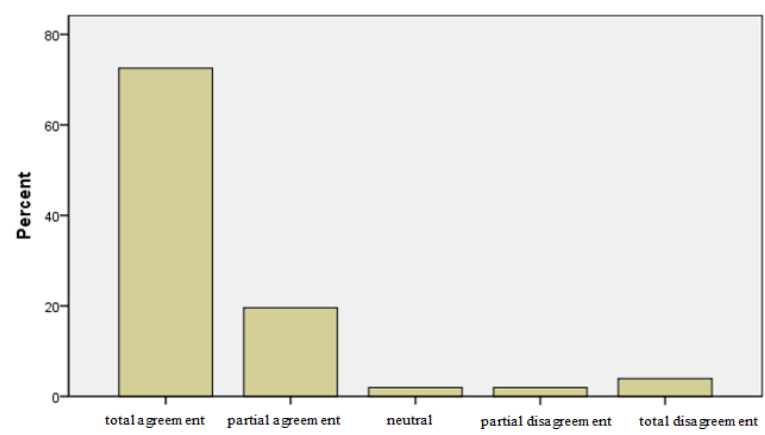


Graph 9. From self- awareness derives the confidence necessary for the act of leadership

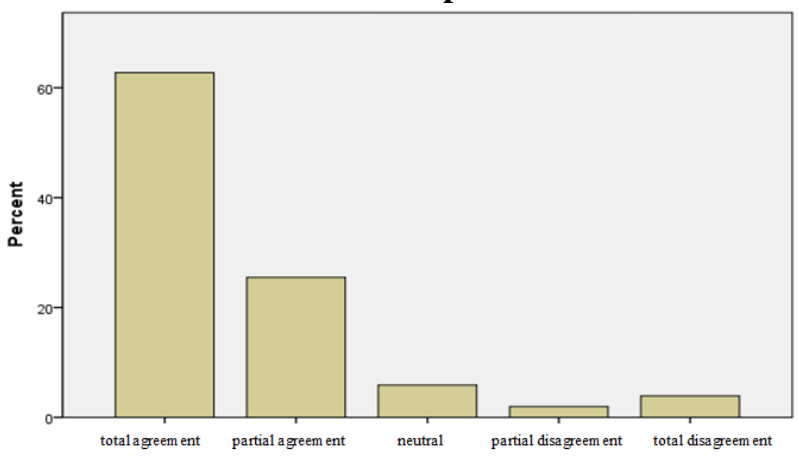

Graph 10. The coherence of the manager with himself strengthens his self confidence

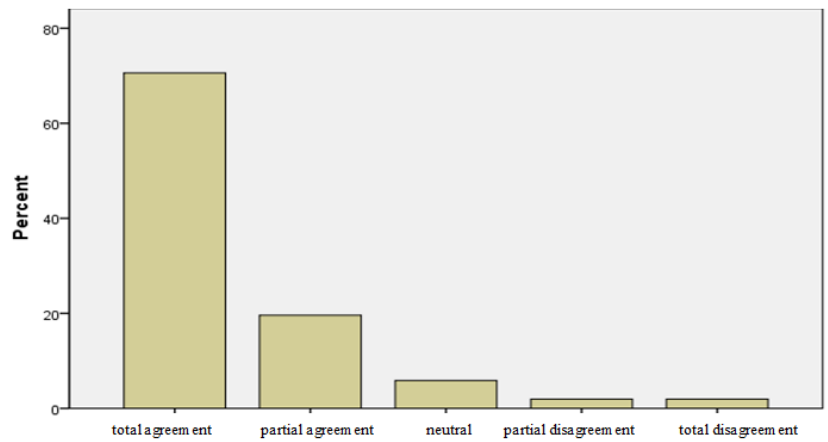

From the above-presented results it is observed that managers recognize the relationship of influence between self-awareness and self-confidence and increase its credibility towards employees, validates hypotheses 2.1. and 2.2.

The last section of the questionnaire - the degree of appreciation for impact of personal qualities on reflective management practices, recorded the following results:

a) analysis and self-reflection $-54.9 \%$ to a very large extent, $37.3 \%$ to a large extent, $3.9 \%$ to a medium extent, $3.9 \%$ not at all.

b) self-assessment $-62.7 \%$ to a very large extent, $31.4 \%$ to a large extent, $2 \%$ to a medium extent, $2 \%$ to a small extent, $2 \%$ not at all.

c) self-improvement $-60.8 \%$ to a very large extent, $33.3 \%$ to a large extent, $2 \%$ to a medium extent, $2 \%$ to a small extent, $2 \%$ to a very small extent.

d) emotional awareness $-45.1 \%$ to a very large extent, $29.4 \%$ to a large extent, $19.6 \%$ to a medium extent, $5.9 \%$ to a small extent.

e) self-confidence $-58.8 \%$ to a very large extent, $29.4 \%$ to a large extent, $9.8 \%$ to a medium extent, $2 \%$ to a small extent.

f) self-control $-56.9 \%$ to a very large extent, $33.3 \%$ to a large extent, $7.8 \%$ to a medium extent, $2 \%$ to a small extent.

g) ambition $-47.1 \%$ to a very large extent, $45.1 \%$ to a large extent, $3.9 \%$ to a medium extent, $3.9 \%$ to a small extent.

h) initiative $-55.8 \%$ to a very large extent, $31.4 \%$ to a large extent, $7.8 \%$ to a medium extent, $2 \%$ to a small extent.

i) visionary thinking $-66.7 \%$ to a very large extent, $19.6 \%$ to a large extent, $11.8 \%$ to a medium extent, $2 \%$ to a small extent.

j) adaptability $-56.9 \%$ to a very large extent, $29.4 \%$ to a large extent, $11.8 \%$ to a medium extent, $2 \%$ to a small extent.

k) empathy - $51 \%$ to a very large extent, $29.4 \%$ to a large extent, $9.8 \%$ to a medium extent, $9.8 \%$ to a small extent.

l) influence $-47.1 \%$ to a very large extent, $39.2 \%$ to a large extent, $5.9 \%$ to a medium extent, $5.9 \%$ to a small extent, $2 \%$ to a very small extent, $5.9 \%$ not at all.

m) team spirit and collaboration $-70.6 \%$ to a very large extent, $19.6 \%$ to a large extent, $7.8 \%$ to a medium extent, $2 \%$ to a very small extent.

n) inspiration $-52.9 \%$ to a very large extent, to a large extent $33.3 \%$, to an average extent $13.7 \%$.

o) facilitating and managing change $-45.1 \%$ to a very large extent, $43.1 \%$ to a very large extent, $7.8 \%$ to a large extent, $2 \%$ to a very small extent. 


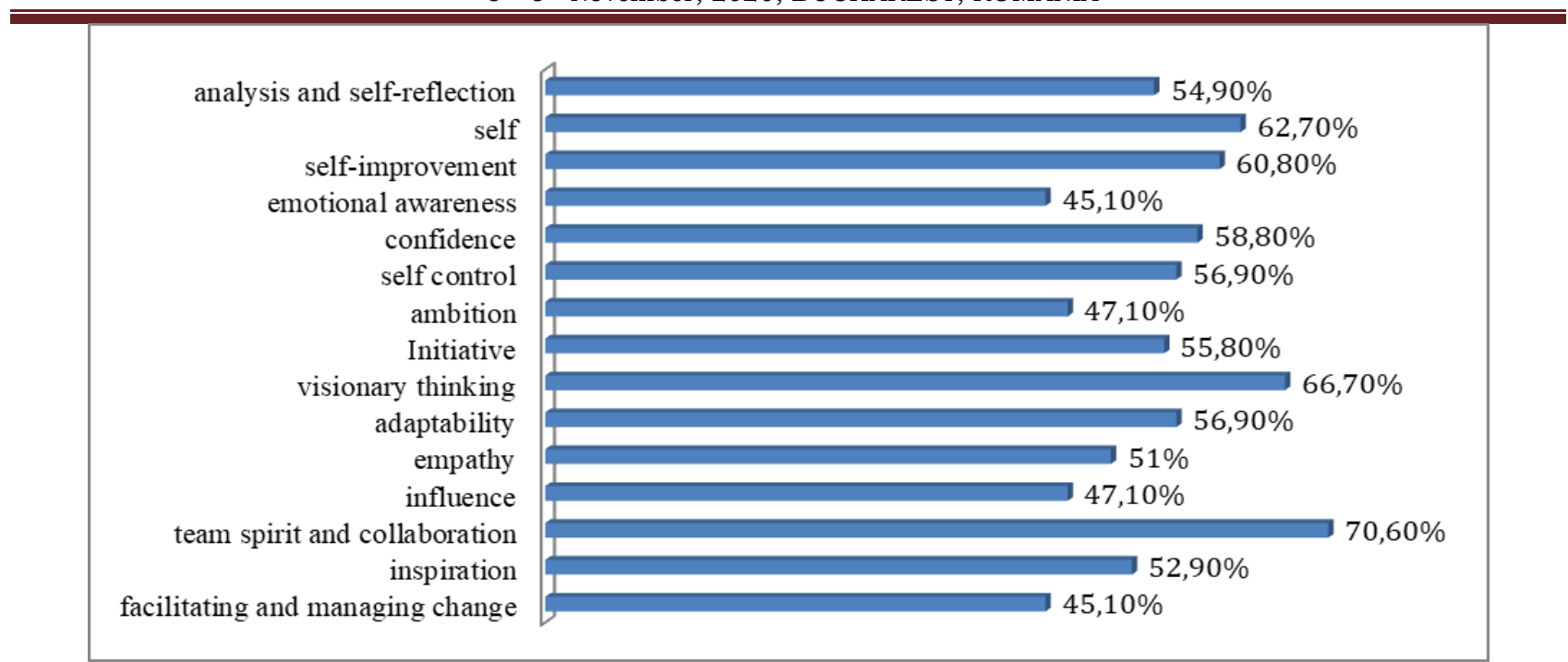

Figure 3. Managers' perception for impact of personal qualities on managerial practices

Source: author

In the perception of the surveyed managers, the fundamental personal qualities in the act of leading the school organization are ranked as follows: team spirit and collaboration, visionary thinking, self-assessment, self-improvement, self-confidence and self-control, the last two places emotional awareness and facilitation and change management, validates hypothesis 3.1 .

\section{CONCLUSIONS}

The analysis of the research shows the following conclusion, the managerial practices are influenced by personal development by involving the manager in processes of (self) reflection on himself, but also on employees, so as to overcome the challenges imposed by the process of organizational change, at the center of his reflective managerial practices placing personal and leadership qualities. The manager who undertakes a process of personal development researches the means to acquire a better self- awareness, will make an in-depth reflection on himself, his values, his personal goals, his relationships with other members of the organization, he will agrees with those of its employees and of the organization. For the manager, self- awareness is the fundamental factor of his future performance and of the organization. He must really be able to take a realistic and critical view of his own dispositions, resources, motivations and beliefs. This deep awareness of himself will allow him to increase his positive influence on his teams and his environment, to manage change and resistance to change.

Limitations of the research: because the research method used is a questionnaire, and some of the answers provided are related to the subjectivity of the respondents, but also the fact that the sample was not extremely large, may be the factors that diminish the degree of objectivity of the research.

Conclusions of the research in order to streamline the management activity, we consider that the following proposals would be opportune:

a) At the level of pre-university education, the management does not include the issue of personal development as a managerial practice and it is imperative to integrate in the master programs in the educational management of courses on this topic.

b) At the level of the Teaching Staff House, training offers can be proposed on the topic of personal development practices of school managers.

c) At the level of each County Center of Resources and Educational Assistance, the managers in collaboration with the experts in counseling and personal development can be instructed to adopt those reflective managerial practices that will support them in the act of leading the organization. 
In the future we propose in-depth research on personal development issues by achieving a double perspective on the phenomenon implemented in the managerial practices, through studies on identifying the perspective of employees in the school organization, but also direct beneficiaries of education (students-parents-school community).

The research could become a starting point for the analysis and self-evaluation of the reflective practices of school managers, at national level, in order to make them more efficient, with the possibility of developing a standard tool for quantifying them (self-assessment questionnaire). Also, by expanding reflective managerial practices, managers want to practice leadership, with which they will be able to overcome the challenges generated by change in their school organization.

\section{REFERENCES}

Adair, J., (2014). How to train leaders. The seven key principles for the effective development of leaders. Bucuresti. Ed.: Meteor Publishing.

Armstrong, M., (2005). Managing performance-Management in action. Chartered Institute of Personal and Development. CIPD House. Camp Road. London.

Blau, G., (1993). Operationalizing direction and level of effort and testing their relationships with individual job performance. Organizational behavior and human decision processes.55.

Bourner, T., (1996). Personal development to improve management performance. Management development review. 9 (6).

Bratchenko, S.L., Mironova, M.R., (1997). Personal growth and its criteria. Psychological problems of personal self-realization. $\mathrm{SPb}$.

Coriat, B., Guennif, S., (2000). Uncertainty, trust and institution, in Confidence in question. Cahiers de Socio-Economie. l'Harmatan logiques sociales.

Deming, E.W., (1994). in Whitney J.O., The trust factor: Liberating profits and restoring corporate vitality. New York: McGraw-Hill

Dinu, V., Săvoiu, G., Dabija, D.-C., (2017). To conceive, write and publish a scientific article - an approach in the context of economic research. Bucharest: ASE.

Goleman, D., (1999). Emotional Intelligence. Robert Laffont.

Goleman D., Boyatzis R., \& Annie Mckee R., (2002). Primal leadership: Realizing the power of emotional intelligence. Boston: Harvard Business School.

Kouzes J., Pozner, B., (1991). The Challenge of Leadership. Afnor Management.

Kubr, M., (1992). Management Consulting - Management Consultant's Manual. Bucharest. AMCOR Publishing House.

Lagace, R., (1991). An Exploratory Study of Reciprocal Trust Between Sales Managers and Salespersons. Journal of Personal Selling and Sales Management. 11 (2).

Marin, N., (2002). Through self-knowledge, to the extent that it creates a climate of trust between him and his employees, will the manager be able to involve his employees in order to ensure performance of the organization? - Research-Action Thesis. University of Evry-Vald'Essonne. DESS of Management of Men \& Teams.

Maurer, R., (2009). Introduction to change without migraines. Maurer and associates, USA, apud Tudor, L., Change management. Employee resistance to organizational change. Romanian Journal of Statistics - Supplement no.9/2014, Retrieved from http://www.revistadestatistica.ro/suplement/wp content/uploads/2014/11/RRSS09_2014_A2_ro.pdf.

Pruit, G., (1981). Negotiation Behavior. New York: Academic Press. 
Revans, R.W., (1971). Developing effective managers - A new approach to business education. Praeger Publishers.

Ristea, A.L., Ioan-Franc, V., Popescu, C., (2020). Metodică în cercetarea științifică, Ed. a II-a, Expert.

Rogers, C., (1998). The development of the person. Dunod.

Sosik, J., (2001). Self-other agreement on charismatic leadership relationships with attitudes and managerial performance. Group \& Organization Management. 26 (4).

Whetten, D.A., Cameron, K. S., (2011). Developing management skills (8th ed.). Upper Saddle River, N.J., Prentice Hall/ Pearson. 